\title{
Risiko Harga Ayam Broiler Pola Kemitraan dan Mandiri di Kabupaten Bekasi
}

\section{(Risk Of Partnership And Independent Broiler Chicken Prices In Bekasi District)}

\author{
Gita Vinanda $^{*}$, Harianto $^{* *}$, dan Lukytawati Anggraeni $\left.{ }^{* * *}\right)$ \\ *) Program Pascasarjana Program Studi Ilmu Ekonomi Pertanian, Institut Pertanian \\ Bogor \\ **) Departemen Agribisnis, Fakultas Ekonomi dan Manajemen, Institut Pertanian \\ Bogor
}

${ }^{1)}$ Email : gitavinanda90@gmail.com

\begin{abstract}
Constraints often faced by broiler breeders in West Java Province are the selling price of broiler chickens that are not always stable. One of the selling prices of broiler chickens is created by the conditions of demand and supply in the market, so that in certain conditions when the number of broilers increases, the selling price of chicken can be very low and when the number of broilers decreases due to constraints in the production process, the selling price of chicken can increase. The purpose of this study was to measure the level of price risk faced by broiler chickens in Bekasi Regency. This research was conducted in Bekasi Regency, West Java Province. Sampling is done by purposive and snowballing method. The number of samples is divided into 35 independent breeders and 39 partner farmers. Data collection is done through interviews directly with the respondent farmers using a questionnaire. The collected data is then analyzed using the coefficient of variation. The results of the study show that the price risk faced by independent farmers is much smaller than the price risk received by partner farmers.
\end{abstract}

Keywords: broiler chicken, partnership, price risk.

Diterima: 20 Agustus 2018. / Disetujui: 9 Mei 2019

\section{PENDAHULUAN}

Industri peternakan unggas khususnya ayam broiler merupakan industri peternakan yang pertumbuhannya tinggi dibandingkan dengan jenis ternak unggas lainnya. Pesatnya pertumbuhan industri ayam broiler tersebut didukung oleh karakteristik proses produksi yang relatif cepat, tidak memerlukan lahan yang relatif luas, teknologi budi daya telah tersedia, pasar (permintaan) cukup terbuka, dan harga produk yang lebih murah dibandingkan produk ternak lainnya seperti daging sapi dan ayam buras. Pada kegiatan budidaya ayam broiler ( on-farm), mayoritas pelakunya adalah peternak 
rakyat karena modal yang diperlukan relatif kecil. Namun, hanya menguasai 20-30\% produksi ayam broiler nasional (Vinanda, Harianto, \& Anggraeni, 2016) .

Usaha ternak ayam broiler di Kabupaten Bekasi terdapat dua pola, yaitu pola mandiri dan pola kemitraan. Pola mandiri, peternak tidak tergantung pada perusahaan mitra dalam mendapatkan sarana produksi. Lain halnya dengan pola kemitraan, dimana peternak mitra mendapatkan seluruh sarana produksi (DOC, pakan, vaksin dan obat-obatan) dipasok dari perusahaan inti. Peternak mitra sudah ada kejelasan pasar, dimana harus menjual hasil produksinya kepada perusahaan inti dengan harga yang berlaku pada saat itu.

Usaha peternakan ayam broiler biasanya menjumpai beberapa kendala yang merupakan hambatan. Kendala dapat berupa tingginya risiko yang dihadapi. Risiko yang sering ditemukan dalam usaha ternak ayam broiler ini adalah risiko produksi dan risiko harga. Pelaku bisnis harus disertai dengan pengetahuan dan kemampuan dalam meminimalkan risiko. Kendala yang sering dihadapi oleh peternak ayam broiler di Provinsi Jawa Barat yaitu harga jual ayam broiler yang tidak selalu stabil (BPS, 2013). Harga jual ayam broiler salah satunya tercipta karena adanya kondisi permintaan dan penawaran di pasar, sehingga dalam kondisi tertentu saat jumlah ayam broiler meningkat, harga jual ayam bisa sangat rendah dan ketika jumlah ayam broiler menurun karena adanya kendala dalam proses produksi, harga jual ayam bisa meningkat. Harga jual ayam broiler bisa berfluktuatif bahkan hanya dalam hitungan hari.

Risiko utama dari seorang pengambil keputusan diantaranya karena ketidakpastian cuaca, hama, dan penyakit. Indikasi adanya risiko harga ditunjukan oleh harga yang diterima pengambil keputusan berfluktuatif (Patrick, Wilson, Barry, Boggess, \& Young, 1985). Risiko harga sangat ditentukan oleh kekuatan penawaran dan permintaan di pasar. Perbedaan pola juga mengakibatkan risiko yang diterima oleh peternak berbeda. Risiko yang dihadapkan peternak mitra secara teori harusnya lebih kecil jika dibandingkan dengan peternak mandiri. Hal tersebut dikarenakan peternak mitra mendapatkan kepastian input (modal) dan kepastian harga, tetapi peternak mandiri tidak. Akan tetapi, sebagian besar peternak mandiri di Kabupaten Bekasi tidak ada kemauan untuk melakukan pola usaha ternak mitra. Berdasarkan masalah tersebut maka tujuan penelitian ini adalah mengukur tingkat risiko harga yang dihadapi peternakan ayam broiler di Kabupaten Bekasi.

\section{METODE PENELITIAN}

Lokasi penelitian dilakukan di Kabupaten Bekasi, Provinsi Jawa Barat dengan pertimbangan bahwa Kabupaten Bekasi merupakan salah satu daerah yang memiliki tren positif dalam pertumbuhan produksi ayam broiler dan akses untuk ke pasar di daerah Kabupaten Bekasi ini relatif lebih mudah. Penelitian ini dilaksanakan pada bulan November 2014 sampai bulan Agustus 2015.

Jenis data yang digunakan adalah data kerat lintang (cross section) baik yang bersifat kualitatif maupun kuantitatif. Sumber data yang digunakan adalah data primer dan sekunder. Sampel yang digunakan adalah peternak berjumlah sebanyak 74 sampel peternak. Sampel terbagi menjadi 2, yaitu 35 peternak mandiri dan 39 peternak mitra. 


\section{Analisis Risiko Harga}

Beberapa ukuran yang dapat digunakan untuk mengukur penyimpangan diantaranya adalah varians (variance), simpangan baku (standart deviation) dan koefisien variasi (coefficient variation) (Fariyanti, Kuntjoro, Hartoyo, \& Daryanto, 2007). Untuk mengukur risiko harga tidak dilakukan pendugaan seperti pada risiko produksi. Risiko harga di ukur dengan mengukur nilai ekspektasi dan variance harga ayam broiler. Ekspektasi harga dan varians dihitung sebagai berikut (Robison \& Barry, 1987) :

$$
\text { EXPHRG }=p_{t} H R G T+p_{r} H R G R+p_{n} H R G N
$$

Peluang adalah suatu kejadian pada kegiatan usaha yang dapat diukur berdasarkan pengalaman yang telah di alami pelaku bisnis dalam menjalankan usahanya. Pada kondisi aktual mengukur peluang kejadian dapat dilakukan dengan melihat frekuensi dari masing-masing kejadian untuk periode waktu tertentu. Peluang adalah kuantifikasi ketidakpastian seseorang yang dinyatakan dalam bilangan antara 0-1. Untuk menggambarkan tingkat kepercayaan seseorang terhadap kejadian yang mungkin terjadi dari suatu kejadian yang tidak pasti.

$$
\begin{aligned}
\operatorname{VARHRG}= & p_{t}[H R G T-E X P H R G]^{2}+p_{r}[H R G R-E X P H R G]^{2} \\
& +p_{n}[H R G N-E X P H R G]^{2}
\end{aligned}
$$

Nilai varians berbanding lurus dengan nilai penyimpangan dan risiko. Semakin kecil nilai varians, maka semakin kecil penyimpangannya dan semakin kecil tingkat risiko yang dihadapinya dalam menjalankan usaha.

$$
\sigma=\sqrt{\sigma}
$$

Standar deviasi dapat di ukur dari akar kuadrat nilai variansnya. Secara matematis rumus menghitung standar deviasi dapat dilihat pada persamaan 3. Nilai yang ditunjukkan dari perhitungan standar deviasi memiliki arti yang sama dengan nilai varians. Dimana semakin kecil nilai standar deviasi, maka semakin kecil risiko yang dihadapinya.

$$
C V \quad=\frac{\sigma}{\text { EXPHRG }}
$$

Nilai koefisien variasi dapat diukur dari rasio standar deviasi dengan expected return. Secara matematis nilai koefisien variasi dapat dilihat pada persamaan 4. Semakin kecil nilai koefisien variasi, maka akan semakin rendah tingkat risiko yang dihadapi. Koefisien variasi adalah angka yang menunjukkan perbandingan antara risiko yang harus ditanggung dengan pendapatan tunai yang akan diperoleh. Dengan kata lain, koefisien variasi digunakan untuk membandingkan risiko yang dihadapi terhadap return atau pendapatan yang diterima. 


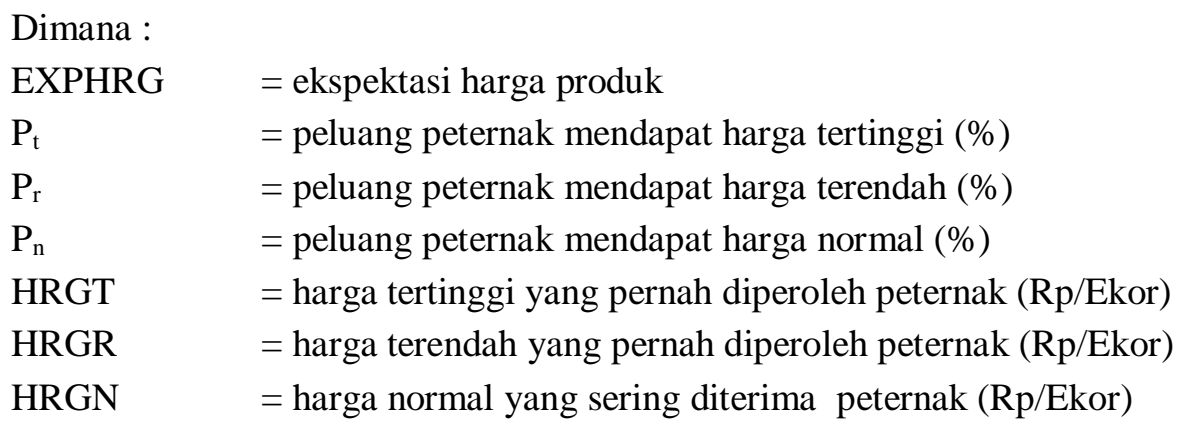

\section{HASIL DAN PEMBAHASAN}

Penilaian risiko didasarkan pada pengukuran penyimpangan terhadap return dari suatu aset. Beberapa ukuran yang dapat digunakan untuk mengukur penyimpangan tersebut adalah varians (variance), standart deviasi (standard deviation), koefisien variasi (coefficient variation). Ukuranukuran tersebut merupakan ukuran statistik yang dapat digunakan untuk mengukur tingkat risiko harga yang terjadi pada harga jual yang dilakukan oleh peternak.

Berdasarkan data yang diperoleh, diketahui bahwa harga tertinggi selama dua periode terakhir penjualan yang dilakukan peternak mandiri adalah Rp 20500.00 per kilogram, harga penjualan terendah sebesar Rp 14000.00 per kilogram dengan rata-rata dari dua periode penjualan sebesar Rp 17 278.57 per kilogram. Harga tertinggi selama dua periode penjualan yang dilakukan peternak mitra adalah sebesar Rp 19 500,00 per kilogram, harga terendah sebesar Rp 13800.00 per kilogram dengan rata-rata harga dari dua periode terakhir sebesar Rp 16819.23 per kilogram.

Berdasarkan hasil dapat disimpulkan bahwa terdapat perbedaan harga antara peternak mandiri dengan peternak mitra. perbedaan harga tersebut berdampak terhadap pendapatan yang diterima oleh peternak ayam broiler. Secara teori, kemitraan mampu memberikan jaminan harga dan kepastian pasar kepada peternak. Tetapi pada penelitian ini kemitraan tidak mampu memberikan jaminan harga kepada peternak yang bermitra. Kemitraan dalam penelitian ini hanya mampu memberikan kepastian pasar kepada peternak yang bermitra dengan perusahaan inti. Kepastian pasar yang dimaksud dalam penelitian ini adalah dimana perusahaan inti mempunyai kewajiban untuk memasok ayam ke pasar tertentu setiap harinya dan ayam tersebut di pasok dari peternak yang bekerja sama dengan perusahaan inti.

Tabel 1. Rata-rata harga ayam broiler (Rp/ekor) dan peluang yang diperoleh peternak ayam broiler di Kabupaten Bekasi.

\begin{tabular}{lllll}
\hline Uraian & \multicolumn{2}{c}{ Mandiri } & \multicolumn{3}{c}{ Mitra } \\
\cline { 2 - 5 } & Rata-rata & Std. Deviasi & Rata-rata & Std. Deviasi \\
\hline Harga terendah & 15240 & 770.71 & 15355 & 572.42 \\
Harga normal & 19186 & 702.25 & 16948 & 629.63 \\
Harga tertinggi & 17342 & 545.84 & 18944 & 404.45 \\
Peluang rendah & 0.21 & - & 0.35 & - \\
Peluang normal & 0.21 & - & 0.42 & - \\
Peluang tinggi & 0.58 & - & 0.23 & -
\end{tabular}




$\begin{array}{lllll}\text { Ekspektasi harga } & 17278 & 2955 & 16819 & 1176\end{array}$

Sumber : Data Primer 2015 (Diolah)

\section{Peluang}

Peluang menunjukkan distribusi frekuensi terhadap suatu kejadian. Kondisi lingkungan internal maupun eksternal dapat mempengaruhi besar atau kecilnya nilai suatu peluang. Peluang yang didapatkan oleh peternak mandiri maupun mitra mempunyai peluang yang berbeda-beda untuk mendapatkan harga yang rendah, normal ataupun tinggi. Peluang untuk peternak mandiri dari dua periode sebesar 0.214 untuk harga rendah, 0.572 harga normal dan 0.214 harga tinggi. Sedangkan peluang peternak mitra dari dua periode sebesar 0.346 untuk harga rendah, 0.423 harga normal dan 0.231 harga tinggi.

\section{Pengembalian yang Diharapkan}

Selain menghitung peluang, penting juga untuk menghitung nilai pengembalian yang diharapkan (expected return) dari suatu usaha yang dijalankan. Nilai expected return dapat dihitung dengan mengakumulasikan seluruh nilai penjualan ayam broiler pada suatu periode yang dikalikan dengan peluang kejadiannya. Berdasarkan hasil perhitungan, diketahui bahwa nilai expected return penjualan ayam broiler peternak mandiri sebesar Rp 17278.57 per kilogram. Sedangkan expected return penjualan yang dilakukan peternak mitra sebesar Rp 16819.23 per kilogram.

\section{Varians}

Varians merupakan akumulasi selisih kuadrat dari return dengan expected return yang dikalikan dengan peluang dari setiap periode penjualan. Berdasarkan hasil perhitungan diperoleh nilai varians harga penjualan yang dilakukan peternak mandiri sebesar 1708 328.07. Sedangkan varians harga penjualan ayam broiler yang dilakukan peternak mitra sebesar 1829 268.75. Berdasarkan nilai variansnya, dapat diketahui bahwa penjualan ayam broiler yang dilakukan peternak mandiri memiliki nilai varians yang lebih kecil dibandingkan dengan nilai varians peternak mitra. Hal ini menunjukkan bahwa penyimpangannya lebih kecil dan tingkat risiko harga peternak mandiri lebih kecil dibandingkan dengan peternak mitra.

\section{Standar Deviasi}

Nilai standar deviasi dapat diperoleh dengan menghitung akar kuadrat dari nilai varians. Berdasarkan hasil perhitungan, diperoleh nilai standar deviasi harga penjualan peternak mandiri sebesar 1 307.03. Sedangkan standar deviasi penjualan peternak mitra sebesar 1 352.50. Berdasarkan nilai standar deviasinya, dapat diketahui bahwa penjualan peternak mandiri memiliki standar deviasi yang lebih kecil yang menunjukkan tingkat risiko harga yang lebih kecil.

\section{Koefisien Variasi}

Nilai koefisien variasi dapat dihitng dengan mengukur rasio dari nilai standar deviasi dengan tingkat pengembalian yang diharapkan (expected return). Berdasarkan hasil perhitungan yang diperoleh nilai koefisien variasi harga penjualan yang dilakukan peternak mandiri sebesar 0.076 , sedangkan nilai koefisien variasi yang dilakukan peternak mitra sebesar 0.080. Berdasarkan nilai koefisien variasinya, dapat diketahui bahwa penjualan yang dilakukan peternak mandiri memiliki nilai koefisien variasi yang lebih kecil yang menunjukkan tingkat risiko harga yang lebih kecil jika dibandingkan dengan peternak mitra. 
Jika dilihat dari tingkat pengembalian yang diharapkan, penjualan yang dilakukan peternak mandiri lebih besar jika dibandingkan dengan penjualan yang dilakukan peternak mitra. Begitu juga jika dilihat dari tingkat risikonya. Jika dilihat dari nilai varians, standar deviasi maupun koefisin variasi, secara keseluruhan nilainya pada peternak mandiri lebih kecil jika dibandingkan dengan peternak mitra. Berdasarkan nilai koefisien variasi, dari setiap Rp 1 yang diharapkan peternak mandiri, maka akan ada risiko sebesar Rp 0.076. Sedangkan jika peternak mitra, dari Rp 1 yang diharapkan akan ada risiko harga yang dihadapi sebesar Rp 0.080. Hal ini berbeda dengan penelitian yang dilakukan oleh (Effiong, Enyenihi, E, \& George, A, 2014) dimana peternak skala kecil sangat riskan terhadap risiko. Dalam penelitian ini, peternak mandiri yang terdapat di lapangan merupakan peternak dengan skala dibawah 5000 ekor per peternak.

Pengukuran tingkat risiko harga ayam broiler secara lebih jelas dapat dilihat pada Tabel 2.

Tabel 2. Hasil perhitungan risiko harga peternak mandiri dan peternak mitra

\begin{tabular}{lll}
\hline Ukuran & Penjualan peternak mandiri & Penjualan peternak mitra \\
\hline Varian & 1708328.07 & 1829268.75 \\
Standar deviasi & 1307.03 & 1352.50 \\
Koefisien variasi & 0.076 & 0.080 \\
\hline
\end{tabular}

Sumber : Data primer 2015 (diolah)

Berdasarkan Tabel 2, dapat dilihat dari risiko usaha ternak, bahwa risiko harga yang dihadapi peternak mandiri lebih kecil. Hal ini dikarenakan, peternak mandiri tidak mempunyai kewajiban untuk memasok ayam broiler, sedangkan peternak mitra mempunyai kewajiban untuk menyediakan atau memanen ayam kepada pedagang atau pasar setiap hari sesuai dengan kebutuhan pasar. Peternak mandiri akan menahan ayam jika harga tidak baik. Biasanya peternak mandiri akan menahan ayam sampai ayam berbobot maksimum sebesar 2 kilogram. Jika pada saat ayam berbobot 2 kilogram, harga ayam tidak juga membaik, peternak mandiri terpaksa menjual ayamnya. Peternak mitra biasanya akan menjual ayam dengan harga berapapun yang berlaku pada saat itu. Peternak mitra tidak ingin mengambil risiko untuk menahan ayam jika harga tidak bagus. Hal tersebut dikarenakan, jika peternak mitra menahan ayam, maka pakan yang digunakan akan lebih banyak. Berdasarkan Tabel 7, pendapatan peternak mandiri lebih besar jika dibandingkan dengan peternak mitra. Hal itu juga diperkuat bahwa peternak mitra di Kabupaten Bekasi lebih berisiko dibandingkan peternak mandiri. Hal ini menjadi salah satu alasan mengapa peternak mandiri di daerah penelitian enggan melakukan kemitraan.

Harga ayam hidup (live bird) dapat berfluktuasi tiap hari bahkan harga yang diterima antar peternak bisa berbeda. Hal tersebut karena harga jual ayam tergantung dari berat bobot ayam, semakin kecil bobot ayam akan semakin tinggi harganya tetapi penerimaan yang diterima peternak tidak terlalu besar karena harga ayam didaerah penelitian adalah rupiah per kilogram. Sebaliknya jika bobot ayam broiler semakin besar maka harga jualnya akan semakin kecil. Tetapi sebagian besar peternak mandiri lebih senang menjual dengan bobot yang lebih besar (kurang dari 2 kilogram) karena penerimaan yang didapatkan akan besar jika dibandingkan dengan menjual ayam dengan bobot kecil. Biasanya peternak mandiri akan menjual ayam broielr berpatokan pada harga posko yang dapat dilihat pada internet. Tetapi harga posko tersebut tidak bisa jadi jaminan peternak mandiri akan mendapatkan harga yang sudah ditetapkan. Harga bisa saja di bawah atau di atas harga posko. Lain halnya peternak mitra, 
peternak mitra biasanya menjual live bird berdasarkan harga pokok produksi yang sudah dihitung. Tetapi peternak mitra juga berpatokan pada harga posko. Biasanya peternak mitra akan menjual ayam berapapun harganya pada pelanggan tetap.

\section{KESIMPULAN}

Risiko harga yang dihadapi peternak mandiri jauh lebih kecil jika dibandingkan dengan risiko harga yang diterima oleh peternak mitra.

\section{DAFTAR PUSTAKA}

BPS. (2013). Statistik Indonesia. Jakarta: Badan Pusat Statistik.

Effiong, E. O., Enyenihi, E, A., \& George, A, A. (2014). Analysis of Farming Risk among Small Scale Poultry Farmers in Etim Ekpo Local Government Area of Akwa Ibom State, Nigeria. Nigerian Journal of Agriculture Food and Environment, 10(1), 59-64.

Fariyanti, A., Kuntjoro, K., Hartoyo, S., \& Daryanto, A. (2007). Pengaruh Risiko Produksi dan Harga Kentang Terhadap Prilaku Produksi Rumahtangga Petani di Kecamatan Pangalengan Kabupaten Bandung (The Influence of Potato's Price and Production Risk on Farm Household Production Behavior in Pangalengan Bandung). Jurnal Agribisnis Dan Ekonomi Pertanian, 1(1).

Patrick, G. R., Wilson, P. N., Barry, P. J., Boggess, W. G., \& Young, D. . (1985). Risk Perceptions and Management Responses: Producers Generated-Hypotheses for Risk Modelling. Journal of Agricultural and Applied Economics, 17(2), 231-238.

Robison, L. ., \& Barry, P. . (1987). Competitive Firm's Response to Risk. Macmillan.

Vinanda, G., Harianto, H., \& Anggraeni, L. (2016). Risiko Produksi Ayam Broiler dan Preferensi Peternak di Kabupaten Bekasi. Jurnal Manajemen Dan Agribisnis, 13(1), 50. 